\title{
Survey of the management of Chlamydia trachomatis infection of the cervix
}

\author{
K W Radcliffe, D Rowen, D E Mercey, J S Bingham
}

\begin{abstract}
A questionnaire was sent to all genitourinary medicine (GUM) clinics in the United Kingdom. Physicians were asked whether women attending the clinics were routinely screened for Chlamydia trachomatis, what treatment was given and whether and how a test of cure (TOC) was carried out after treatment; $94.5 \%$ of clinics responded. Screening for chlamydia was not carried out routinely in $4.8 \%$ of clinics. Treatments and their costs varied widely between clinics; six antibiotics were prescribed in 35 different ways. Less than half the clinics used regimens compatible with the advice of the World Health Organisation (WHO) and the Centers for Disease Control (CDC). Antibiotics in larger doses and/or for longer durations than those known to be effective were prescribed in $85 \%$ of clinics. Unnecessary routine TOC were carried out by $86 \%$ of clinics in 29 different ways. Sixteen percent of clinics carried out TOC immediately after completion of therapy, which is inadvisable on technical grounds. There is a need to standardise and improve the treatment and follow-up of chlamydial infection in women attending GUM clinics.
\end{abstract}

\section{Introduction}

Two previous surveys attempted to assess the availability of chlamydial diagnostic services in departments of genito-urinary medicine (GUM) in the United Kingdom (UK). They were carried out in $1984^{1}$ and $1987 .{ }^{2}$ Both had low response rates-54\% and $67 \%$ respectively.

This survey was designed to assess: (1) how many GUM clinics in the UK routinely screen female patients for Chlamydia trachomatis; (2) how

\footnotetext{
Department of Genitourinary Medicine, The Middlesex Hospital, London

K W Radcliffe, D E Mercey, J S Bingham

Department of Genitourinary Medicine, Addenbrooke's Hospital, Cambridge

D Rowen
}

chlamydial infection of the cervix is treated in clinics; (3) how female patients are followed up after treatment.

\section{Methods}

A questionnaire was sent to all 218 departments of GUM in the UK, rather than to individual consultants. If no response was obtained the questionnaire was sent a second time. If there was still no reply the clinics were contacted by telephone in an effort to obtain the necessary information.

The following information was requested: (1) whether or not female patients were routinely screened for $C$ trachomatis, and if so which test or tests were used; (2) which antibiotic was normally used to treat women with chlamydia, including dosage and duration of treatment; (3) whether or not a test of cure (TOC) was routinely performed after women had completed treatment, and if so which test or tests were used and when they were carried out.

\section{Results}

Responses were obtained from 207 clinics $(94.5 \%)$. One hundred and ninety seven clinics, $95.2 \%$ of those replying, routinely screened for chlamydia in female patients. Screening was not done in 10 clinics $(4.8 \%)$. Two of these clinics reported no chlamydial diagnostic service and one reported a very limited service. Table 1 shows the methods used for screening.

Table 1 Microbiological methods used for screening and TOC for chlamydia in female patients

\begin{tabular}{lcc}
\hline & $\begin{array}{l}\text { Screening } \\
\text { Number (\%) } \\
\text { of Clinics }\end{array}$ & $\begin{array}{l}\text { TOC } \\
\text { Number (\%) } \\
\text { of Clinics }\end{array}$ \\
\hline Enzyme immunoassay (EIA) & $100(50 \cdot 8)$ & $90(50 \cdot 6)$ \\
Immunofluorescence assay (DFA) & $54(27 \cdot 4)$ & $48(27 \cdot 0)$ \\
Culture & $23(11 \cdot 7)$ & $22(12 \cdot 4)$ \\
EIA + DFA & $7(3 \cdot 6)$ & $3(1 \cdot 7)$ \\
EIA + Culture & $6(3 \cdot 0)$ & $6(3 \cdot 4)$ \\
DFA + Culture & $4(2 \cdot 0)$ & $4,(2 \cdot 2)$ \\
EIA + DFA + Culture & $0(0)$ & $2(1 \cdot 1)$ \\
Radioimmunoassay & $1(0 \cdot 5)$ & 1 \\
Unclear & $2(1 \cdot 0)$ & $2(1 \cdot 1)$ \\
Total & 197 & 178 \\
\hline
\end{tabular}


Table 2 Antibiotics used in treatment of cervical infection with Chlamydia trachomatis

\begin{tabular}{|c|c|c|c|}
\hline Antibiotic & $\begin{array}{l}\text { Number }(\%) \text { of } \\
\text { clinics using }\end{array}$ & Maximum regime & Minimum regime \\
\hline $\begin{array}{l}\text { Oxytetracycline } \\
\text { Deteclo } \\
\text { Erythromycin } \\
\text { Doxycycline } \\
\text { Minocycline } \\
\text { Tetracycline }\end{array}$ & $\begin{array}{r}74(35 \cdot 7) \\
53(25 \cdot 6) \\
51(24 \cdot 6) \\
21(10 \cdot 1) \\
4(1 \cdot 9) \\
4(1 \cdot 9)\end{array}$ & $\begin{array}{l}2 \mathrm{~g} / \text { day for } 2 \text { weeks } \\
4 \mathrm{tablets} / \text { day for } 2 \text { weeks } \mathrm{t} ; \ldots \\
2 \mathrm{~g} / \text { day for } 10 \text { days } \\
400 \mathrm{mg} / \text { day for } 10 \text { days } \\
200 \mathrm{mg} / \text { day for } 10 \text { days } \\
2 \mathrm{~g} / \text { day for } 1 \text { week }\end{array}$ & $\begin{array}{l}0.5 \mathrm{~g} / \text { day for } 1 \text { week } \\
2 \mathrm{tablets} / \text { day for } 1 \text { week } \\
1 \mathrm{~g} / \text { day for } 1 \text { week } \\
200 \mathrm{mg} \text { stat, } 100 \mathrm{mg} / \text { day for } 6 \text { days } \\
200 \mathrm{mg} / \text { day for } 1 \text { week } \\
1.5 \mathrm{~g} / \text { day for } 1 \text { week }\end{array}$ \\
\hline
\end{tabular}

Six antibiotics were used as standard treatment for chlamydia. However, a total of 35 different regimens were reported. Table 2 shows the maximum and minimum courses prescribed.

TOC were routine in $178(86 \%)$ clinics. The method used was specified by 176 . A single microbiological test was used in $91 \%$, and $9 \%$ used a combination of tests. Enzyme immunoassay (EIA) and direct immunofluorescence assay (DFA) were the most commonly employed techniques (see table 1).

The timing and number of their TOC were reported by 163 clinics. One hundred and thirty nine $(85 \%)$ performed a single TOC, $23(14 \%)$ performed two and one clinic carried out three. Twenty seven clinics $(17 \%)$ performed a TOC immediately after the completion of the treatment. Other clinics did their TOC at varying times up to 12 weeks later. The variation in the number of tests and in their timing resulted in a total of 29 reported methods of carrying out TOC.

\section{Discussion}

Two previous consultant-directed surveys, performed in $1984^{1}$ and $1987,{ }^{2}$ found that $32 \%$ and $21 \%$ respectively of genitourinary physicians who responded had an inadequate or non-existent chlamydia diagnostic service. The results of this survey indicate that there has been further improvement. However, the screening of female patients for chlamydia is still not universal in departments of GUM in the UK.

There is considerable variation in the treatment prescribed for chlamydial infection of the cervix. In their most recent guidelines both the World Health Organisation (WHO) ${ }^{3}$ and the Centers for Disease Control $(\mathrm{CDC})^{4}$ recommended the same antibiotic regimens. First-line therapy is doxycycline $100 \mathrm{mg}$ twice a day or tetracycline $500 \mathrm{mg}$ four times a day for seven days. Alternative therapies are erythromycin $500 \mathrm{mg}$ four times a day for seven days or sulfisoxazole $500 \mathrm{mg}$ four times a day for ten days (or equivalent doses of other sulphonamides).

The results of clinical studies indicate that lower doses are adequate. Tetracycline $1 \mathrm{~g}$ /day, erythromycin $1 \mathrm{~g} /$ day, Deteclo $600 \mathrm{mg} /$ day, and doxycycline $200 \mathrm{mg}$ stat proceeding to $100 \mathrm{mg} /$ day have all been shown to be effective when given for seven days. ${ }^{5-8}$
From the results of this survey, even considering minocycline to be equivalent to doxycycline and oxytetracycline to be equivalent to tetracycline, only $97(47 \%)$ of the 207 clinics who supplied information on treatment used an antibiotic regimen compatible with the advice of the WHO and CDC. Of these clinics $176(85 \%)$ prescribed antibiotics in larger doses and/or for longer durations than those known to be effective in published reports.

There is equally wide variation in the costs of the therapies used. The cheapest regime costs the National Health Service 17p (oxytetracycline $0.5 \mathrm{~g}$ / day for seven days) and the most expensive costs $£ 20.90 \mathrm{p}$ (doxycycline $400 \mathrm{mg} /$ day for ten days). Of the treatments recommended by the WHO and CDC the cheapest costs $68 \mathrm{p}$ (oxytetracycline $2 \mathrm{~g} /$ day for seven days) and the most expensive costs $£ 7 \cdot 32 \mathrm{p}$ (doxycycline $200 \mathrm{mg} /$ day for seven days). The prices quoted are for the generic drugs alone and make no allowance for the cost of packaging and Value Added Tax, or for locally-negotiated pricing agreements.

Eighty six percent of clinics routinely perform a TOC but both the WHO and CDC advise that this is unnecessary. ${ }^{34}$ This recommendation is supported by the following laboratory and clinical evidence: (a) naturally occurring resistance of $C$ trachomatis to the tetracyclines and erythromycin has never been described, (b) in the largest series of women followed after treatment for cervical chlamydial infection, $C$ trachomatis was reisolated in only $10 \%$. Reinfection and not treatment failure was the probable explanation in all cases. ${ }^{10}$ As many clinics perform more than one TOC and/or utilise more than one microbiological method, there would be considerable savings in time, money and discomfort to the patient if this advice was followed.

Apparent treatment failure may result from noncompliance or reinfection through further unprotected intercourse. If the clinician believes a TOC to be necessary it is inadvisable to repeat microbiological tests immediately after finishing treatment. Antigen detection tests such as EIA and DFA may give misleading positive results in this situation due to persisting antigens from non-viable chlamydia. ${ }^{11}$ Culture may fail to detect chlamydiae due to the suppressive action of antibiotics. ${ }^{11}$ In this survey $16 \%$ of clinics incorporated an immediate TOC in their follow-up. 
The results of this survey show that there is a need to reappraise critically the management of chlamydial infection in female patients. Treatment and follow-up should be standardised. It would be possible to save time and resources, and to reduce discomfort and inconvenience to patients, by avoiding unnecessary treatments and investigations. This is particularly relevant at the present time in view of the increasing importance being attached to medical audit.

Address for correspondence: Dr K W Radcliffe, Department of Genitourinary Medicine, Charing Cross Hospital, London W6 9RF, UK.

1 British Co-operative Clinical Group. Survey of diagnostic facilities for Chlamydia trachomatis and herpes simplex virus 1984. Genitourin Med 1987;63:26-7.

2 Royal College of Physicians Committee on Genitourinary Medicine. Chlamydial diagnostic services in the United Kingdom and Eire: current facilities and perceived needs. Genitourin Med 1987;63:371-4.

3 Sexually transmitted diseases treatment strategies. WHO Consultation on development of sexually transmitted disease treatment strategies. WHO/VDT/98.447; 1989.
4 Centers for Disease Control. 1989 sexually transmitted disease treatment guidelines. $M M W R$ 1989;38(S-8):1-43.

5 Schiebel $\mathrm{JH}$, Kristensen JK, Hentzer B, et al. Treatment of chlamydial urethritis in men and Chlamydia trachomatispositive female partners: comparison of erythromycin and tetracycline in treatment courses of one week. Sex Transm Dis 1982;9:128-31.

6 Hunter JM, Sommerville RG. Erythromycin stearate in treating chlamydial infection of the cervix. $\mathrm{Br} J$ Venereal Dis 1984;60:387-9.

7 Waugh MA, Nayyar KC. Triple tetracycline (Deteclo) in the treatment of chlamydial infection of the female genital tract. Br J Venereal Dis 1977;53:96-7.

8 Svensson L, Westrom L, Mardh P-A. Chlamydia trachomatis in women attending a gynaecological out-patient clinic with lower genital tract infection. Br J Venereal Dis 1981;57: 259-62.

9 Mourad A, Sweet RL, Sugg N, et al. Relative resistance to erythromycin in Chlamydia trachomatis. Antimicrob Agents Chemother 1980;18:696-8.

10 Rees A, Tait A, Hobson D, et al. Chlamydia in relation to cervical infection and pelvic inflammatory disease. In: Hobson $\mathrm{D}$, Holmes KK, eds. Non-gonococcal urethritis and related infections. Washington, DC: American Society for Microbiology, 1977.

11 Kellogg JA. Clinical and laboratory considerations of culture vs. antigen assays for detection of Chlamydia trachomatis from genital specimens. Arch Pathol Lab Med 1989;113:453-60.

Accepted for publication 12 October 1990 